\title{
Laterally Graded Multilayer Double-Monochromator
}

\author{
A.T. Macrander ${ }^{*}$, J. Als-Nielsen ${ }^{b}$, C. Liu ${ }^{2}$, S. Krasnicki ${ }^{2}$, J. Maj ${ }^{2}$, D. Mancini ${ }^{2}$, \\ J. Erdmann " P. Gaarde" \\ "Advanced Photon Source, Argonne National Laboratory, Argonne, IL 60439 \\ Diels Bohr Institute, Copenhagen University, Denmark

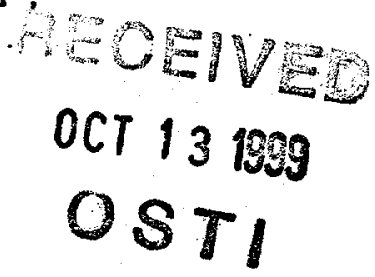

We describe a tunable multilayer monochromator with an adjustable bandpass to be used for reflectivity and grazing incidence diffraction studies on surfaces at energies near $10 \mathrm{keV}$. Multilayers have a bandpass typically 100 times larger than the Si (111) reflection, and by using multilayers an experimenter can significantly increase data collection rates over those available with a Si monochromator. The transmission through 1 and 2 laterally graded multilayer (LGML) reflections was recorded versus photon energy. The identical LGMLs were comprised of 60 bilayers of $\mathrm{W}$ and $C$ on $100 \times 25 \times 3 \mathrm{~mm}$ float glass with a bilayer spacing varying from 35 to $60 \mathrm{~A}$. The average gradient was $0.27 \mathrm{~A} / \mathrm{mm}$ along the long dimension. The rms deviation of the data for the bilayer spacing from a linear fit was $0.36 \AA$ Data were obtained for a nondispersive ( $( \pm$ ) double-muliblayer arrangement. The relative bandpass width (FWHM) when the two multilayers exposed the same bilayer spacing was measured to be $2.2 \%$ with a transmission of $78.7 \pm 1.6$ \%. This value is consistent with the transmission of $88.9 \%$ that we also measured for a single LGML at HASYLAB beamline D4. The bandpass was tunable in the range $1.1 \%$ to $2.2 \%$.

Keywords: X-ray monocbromator, multilayers, graded

\section{INTRODUCTION}

For many reflectivity or diffraction studies $\left[{ }^{[1]}\right.$ a relative bandpass of order $10^{-4}$ or less, typical for Si single-crystat monochromators, is unnecessary. A hundred-fold broader bandpass may be acceptable, in particular for small angle scattering experiments. A hundred-fold increase in intensity would be a pure bonus for such experiments. An extra degree of freedom is obtained by having the bilayer spacing vary laterally across the surface, i.e., a laterally graded multilayer (LGML). By having two LGMLs in series in the conventional non-dispersive double-crystal-like arrangement, one has the possibility of fetting the beam hit slighttly different bilayer spacings on each LGML. We have made preliminary tests on such an optical arrangement.

\section{MULTILAYERS}

Two graded W/C multilayers were grown by DC magnetron sputtering onto float glass substrates in the large deposition system of the Optics Fabrication and Metrology Group of the Advanced Photon Source at Argonne National Laboratory. ${ }^{[2]}$ The grading was produced by changing only the $C$ layer thickness. Specifics for the multilayers are detailed in Table I.

Table I. Individual Graded Multilayer Specifics.

\begin{tabular}{|l|l|}
\hline Substrate size: & $100 \mathrm{~mm} \times 25 \mathrm{~mm} \times 3 \mathrm{~mm}$ \\
\hline Useful area: & $80 \mathrm{~mm} \times 20 \mathrm{~mm}$ \\
\hline Range of bilayer spacing & $35-60 \AA$ \\
\hline W layer thickness & $9.8 \pm 0.4 \AA$ \\
\hline Gradient & $0.27 \AA \mathrm{mm}$ \\
\hline Number of bilayers & 60 \\
\hline Reflectivity & $85-89 \%$ \\
\hline
\end{tabular}

"Correspondence: Email: macrander@aps,anl.gov

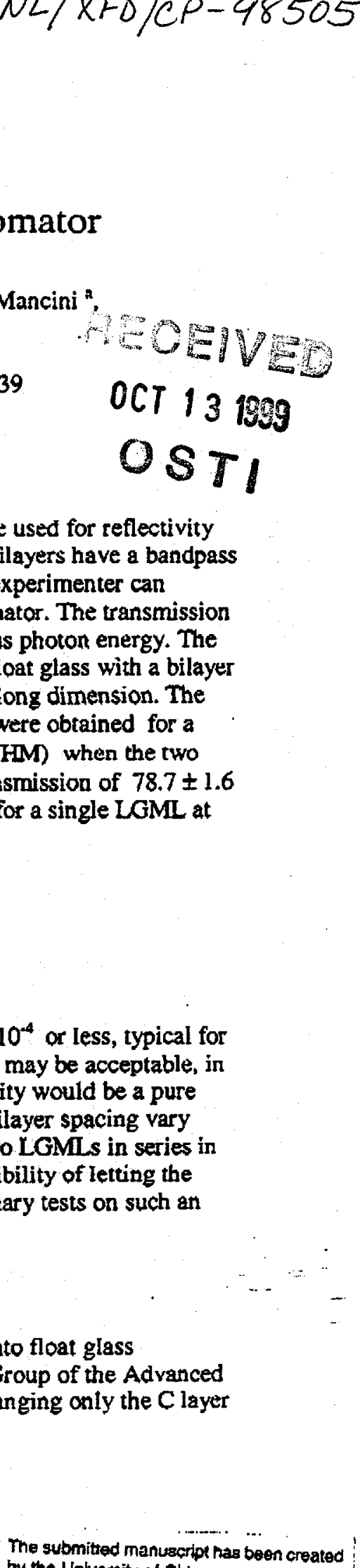
by the Untvertity of Chicago as Operator of Argonne National Laboratory ("Argonne") under Contract No. W-31-109-ENG-38 with the U.S. Department of Energy. The U.S. Government retains for itself. and others acting on its behalf, a paid-up, nonexclusive, irrovocable worldwide license in said enticte to reproduce, prepare derlvalive works, dis. irlbute copies to the public, and perform publicly and display publlaty, by or on behalf of the Government. 


\section{DISCLAIMER}

This report was prepared as an account of work sponsored by an agency of the United States Government. Neither the United States Government nor any agency thereof, nor any of their employees, make any warranty, express or implied, or assumes any legal liability or responsibility for the accuracy, completeness, or usefulness of any information, apparatus, product, or process disclosed, or represents that its use would not infringe privately owned rights. Reference herein to any specific commercial product, process, or service by trade name, trademark, manufacturer, or otherwise does not necessarily constitute or imply its endorsement, recommendation, or favoring by the United States Government or any agency thereof. The views and opinions of authors expressed herein do not necessarily state or reflect those of the United States Government or any agency thereof. 


\section{DISCLAIMER}

Portions of this document may be illegible in electronic image products. Images are produced from the best available original document. 
X-ray reflectivity data were obtained i) on a rotating anode based diffractometer in the OFM Group, ii) at beamline 2BM of the APS, and iii) at beamline D4 at HASYLAB. Basic characterization was done using a rotating anode with a footprint on the sample of $10 \mathrm{~mm} \times 10 \mathrm{~mm}$. A 25 micron pinhole to provide a footprint of $3.6 \mathrm{~mm} \times 0.05 \mathrm{~mm}$ was used to obtain data at beamline 2BM at the APS. For the data taken at HASYLAB the footprint was $1 \mathrm{~mm} \times 4 \mathrm{~mm}$. A representative theta - two-theta scan taken at the APS is shown in Fig. 1. A fit obtained using the IMD code of D. Windt is also shown. ${ }^{[3]}$ Fitted results were obtained for an interface roughness of $4.5 \AA \mathrm{rms}$ for all interfaces and with other parameters as listed in Table I. Data for the lateral variation in the bilayer spacing is shown in Fig.2

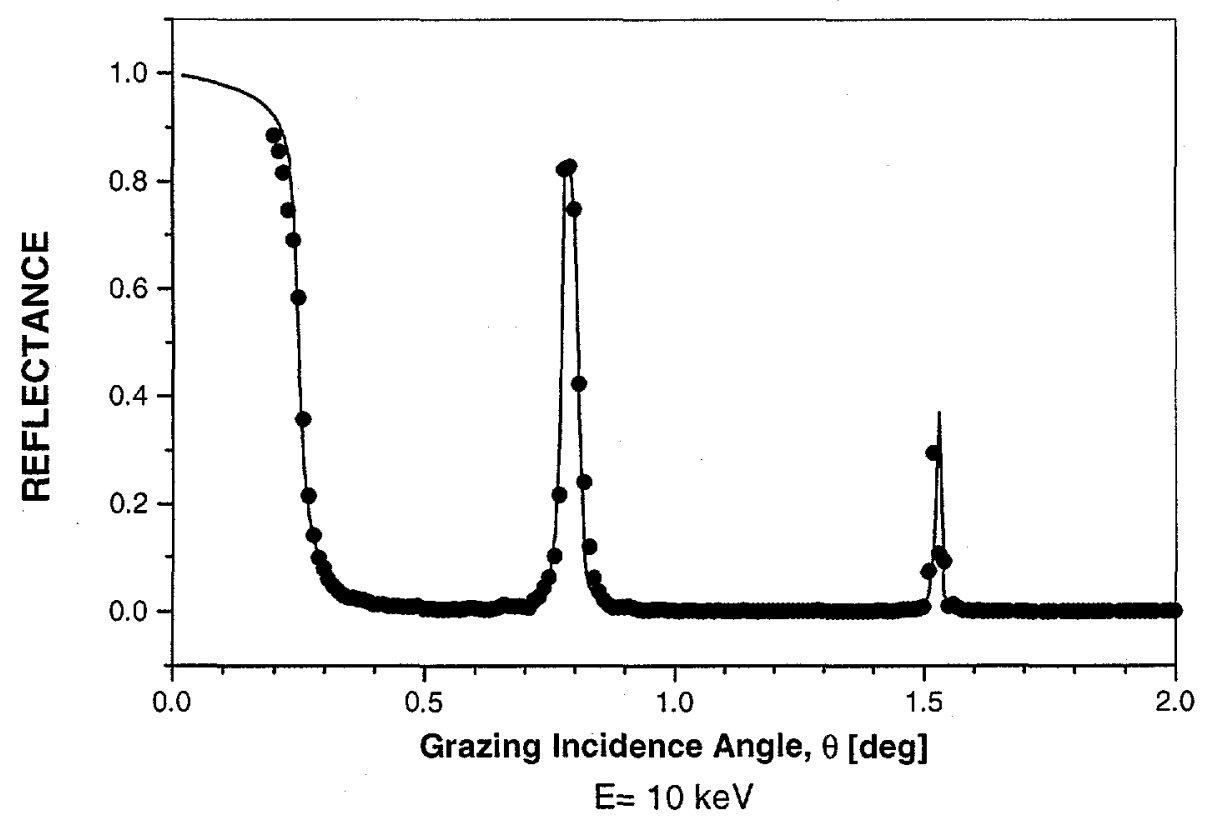

Figure. 1. Theta - two-theta scan taken through a 25 micron pinhole at beamline 2BM of the APS. A fit generated by the IMD code (Ref. 3) is also shown (solid line). For the fit, the layer thickness of the carbon layer is $37.7 \AA$ and the layer thickness of the $\mathrm{W}$ layer is $9.42 \AA$. The roughness of all multilayer interfaces is $4.5 \AA \mathrm{rms}$. The number of bilayers is 60 . A resolution width of $0.006 \mathrm{deg}$ as determined by the slit settings was applied to the IMD results. 


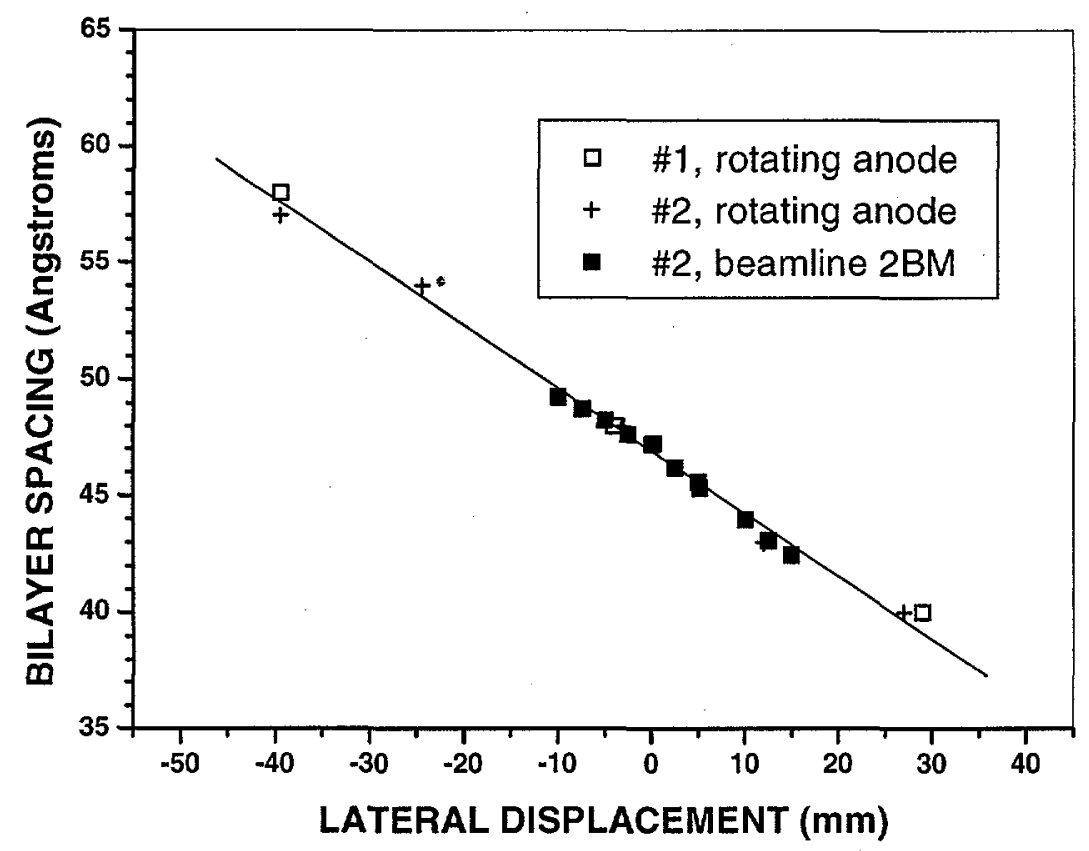

Fig. 2. Combined data for the bilayer spacing as a function of lateral distance as measured from $x$-ray diffraction data (as shown in Fig. 1). Only the $C$ layer thickness was graded, i.e., the $\mathrm{W}$ layer thickness was not changed. Data are shown for both multilayers \#1 and \#2. A least squares linear fit to the data for \#2 is also shown as a straight line. The rms deviation of the bilayer thickness data for \#1 from the fit is $0.36 \AA$.

\section{EXPERIMENTAL ARRANGEMENT AT HASYLAB BEAMLINE D4}

The arrangement used to make the bandpass measurements on the double multilayer configuration is shown in Fig. 3. Data were obtained by tuning the $\mathrm{Si}(111)$ monochromator through the first order of an aligned double - multilayer arrangement. Both multilayers were placed on a two-theta arm centered at the Si monochromator and rotating in the horizontal plane. The incident angles of the two multilayers were kept fixed for the transmission measurements. The detector was an NaI scintillation counter viewing the scattering from a kapton foil placed at 45 deg to the beam. 


\section{Detector}

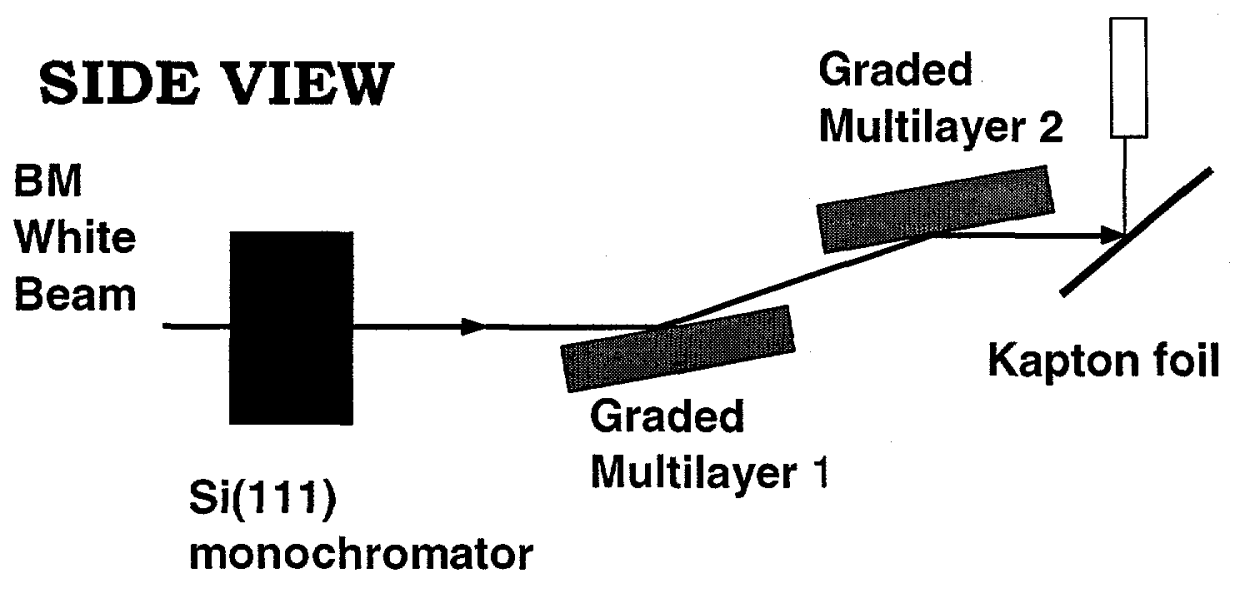

\section{GRADED \\ MULTILAYERS}

\section{TOP VIEW}

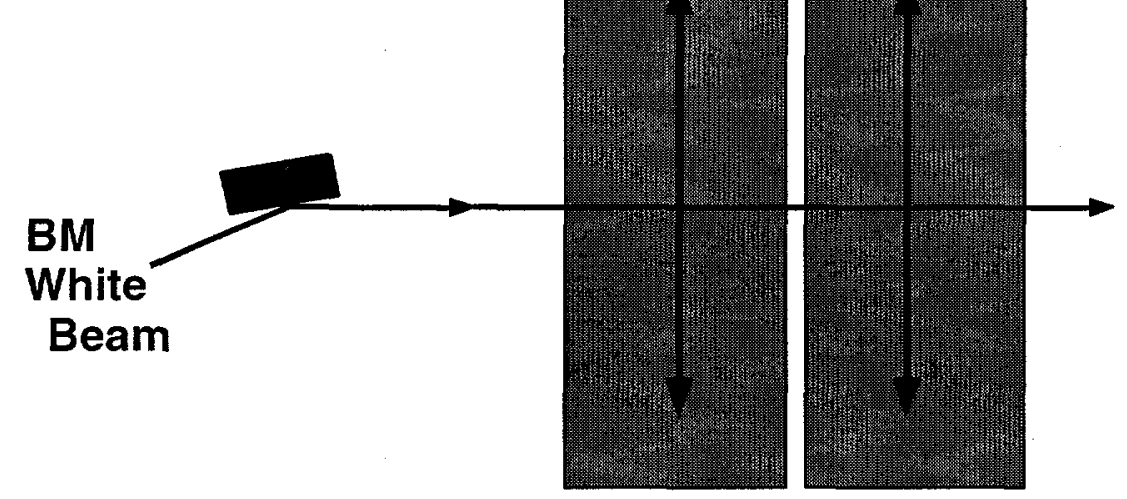

Fig. 3. Optical arrangement for the bandpass measurements. A horizontal divergence of $\sim 0.03 \mathrm{deg}$ was present. This resulted (via the $\mathrm{Si}(111)$ monochromator) in a fan of incident $\mathrm{x}$-rays spanning a bandwidth of $\sim 0.04 \mathrm{keV}$. This is the resolution width for the transmission data.

\section{RESULTS}

Transmission results are shown in Fig. 4 for three different relative lateral displacements. After aligning the first multilayer separately with the beam in the middle of the graded region, the lateral position of the second multilayer labeled as " $0 \mathrm{~mm}$ " was obtained by first adjusting its displacement until the peak transmission value was optimized. Subsequent displacements of the second multilayer were measured with respect to this " 0 " position. The $\mathrm{L}_{\mathrm{nI}}$ absorption edge of $\mathrm{W}$ at $10.2 \mathrm{keV}$ is evident in the data. An error bar for these data is shown that represents \pm one standard deviation. The uncertainty in the transmission results was obtained from counting statistics in the measured signal and from rms fluctuations in incident beam intensity. 


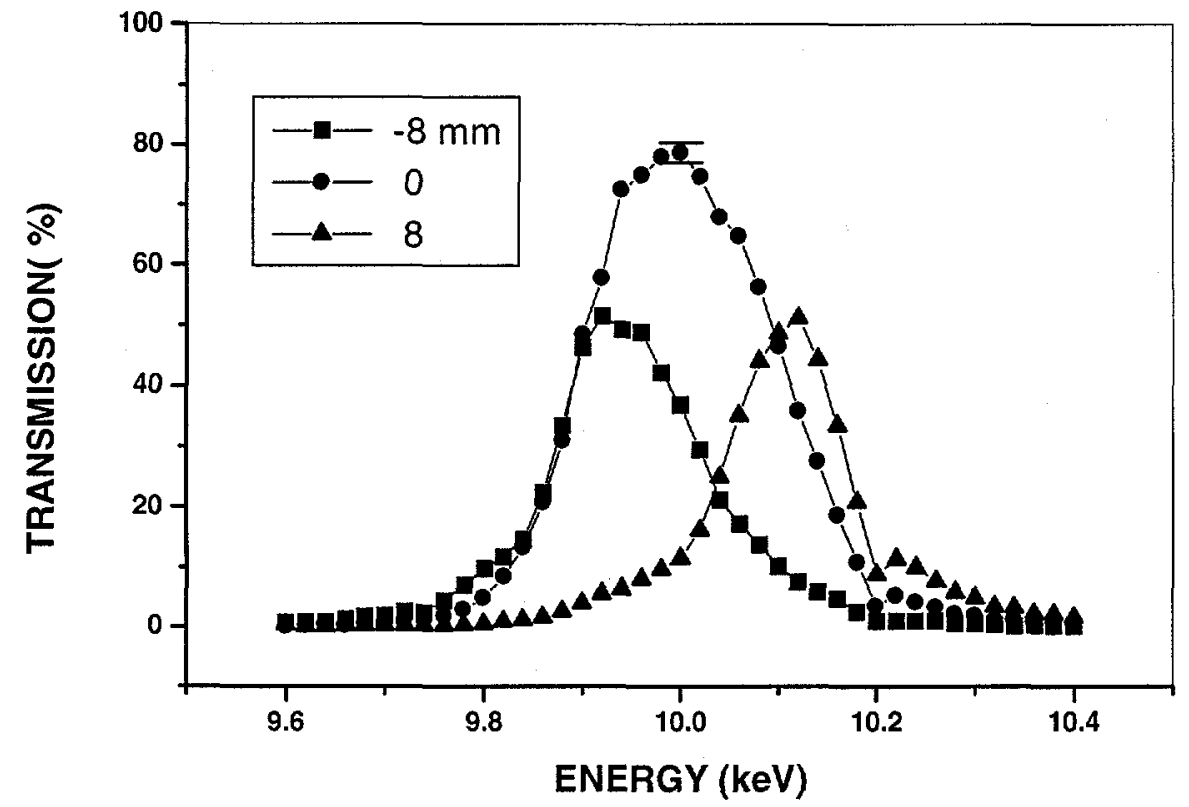

Fig.4 Transmission of the double - multilayer optical arrangement as a function of x-ray photon energy for relative lateral displacements of $-8 \mathrm{~mm}, 0 \mathrm{~mm}$, and $8 \mathrm{~mm}$.

The IMD code ${ }^{[3]}$ can be used to simulate these results. The simulated transmission is the product of the reflectivities for the two multilayers. The calculated spectra must be convolved with a resolution function that arises from the energy spread that is coupled to the horizontal divergence through the Si(111) monochromator. This coupling between divergence and spectral width arises as a result of the (111) Bragg reflection. The energy width of the Gaussian resolution function that was applied within IMD to calculate the reflectivities was $0.050 \mathrm{keV}$, a value consistent with the incident horizontal slit opening $(0.05 \mathrm{~mm})$. The simulated results are shown in Fig. 5 . There is a qualitative agreement between these simulated results and the data. However, there is not full quantitative agreement for the dependence on lateral displacement. This is apparently due to local variations in the bilayer spacing either in each multilayer or in the relative variation between multilayers \#1 and \#2.

The lack of complete agreement between data and simulation notwithstanding, the double multilayer arrangement works as desired, evidenced by the net results for per cent transmission and bandpass as shown in Fig. 6. 


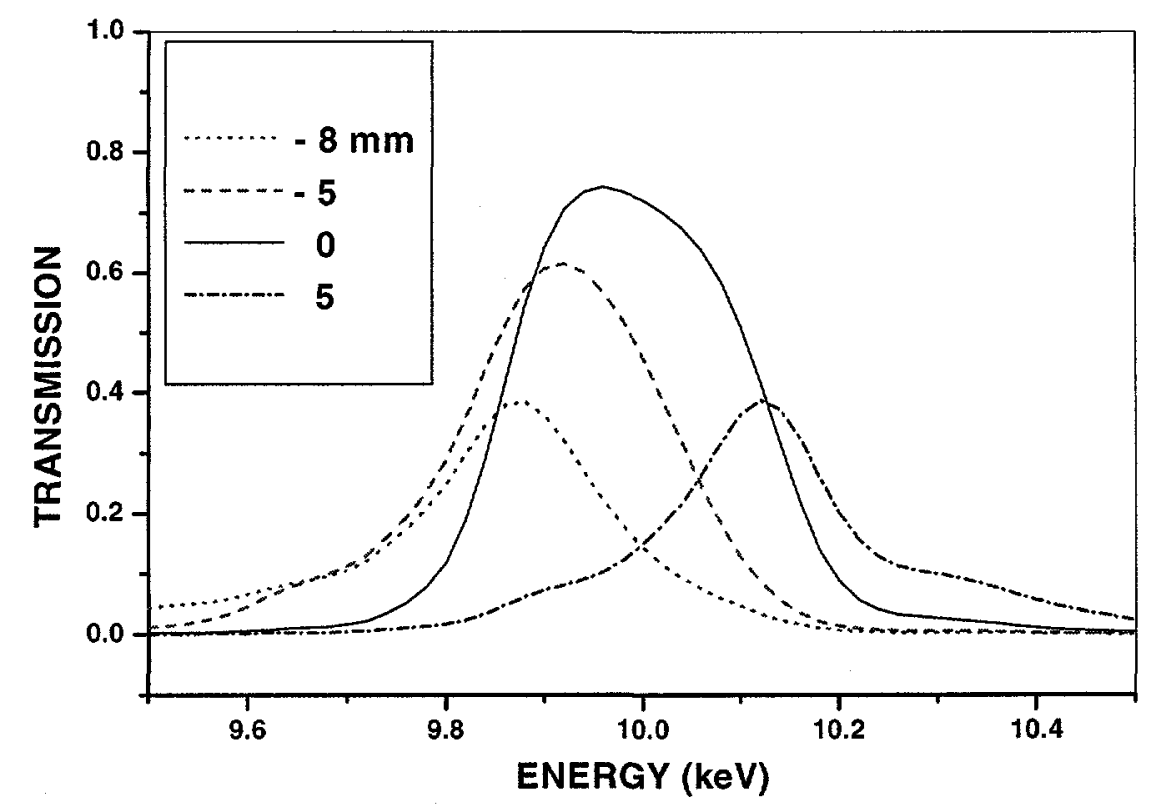

Fig.5. Calculated transmission spectra for the two multilayer optical arrangement.

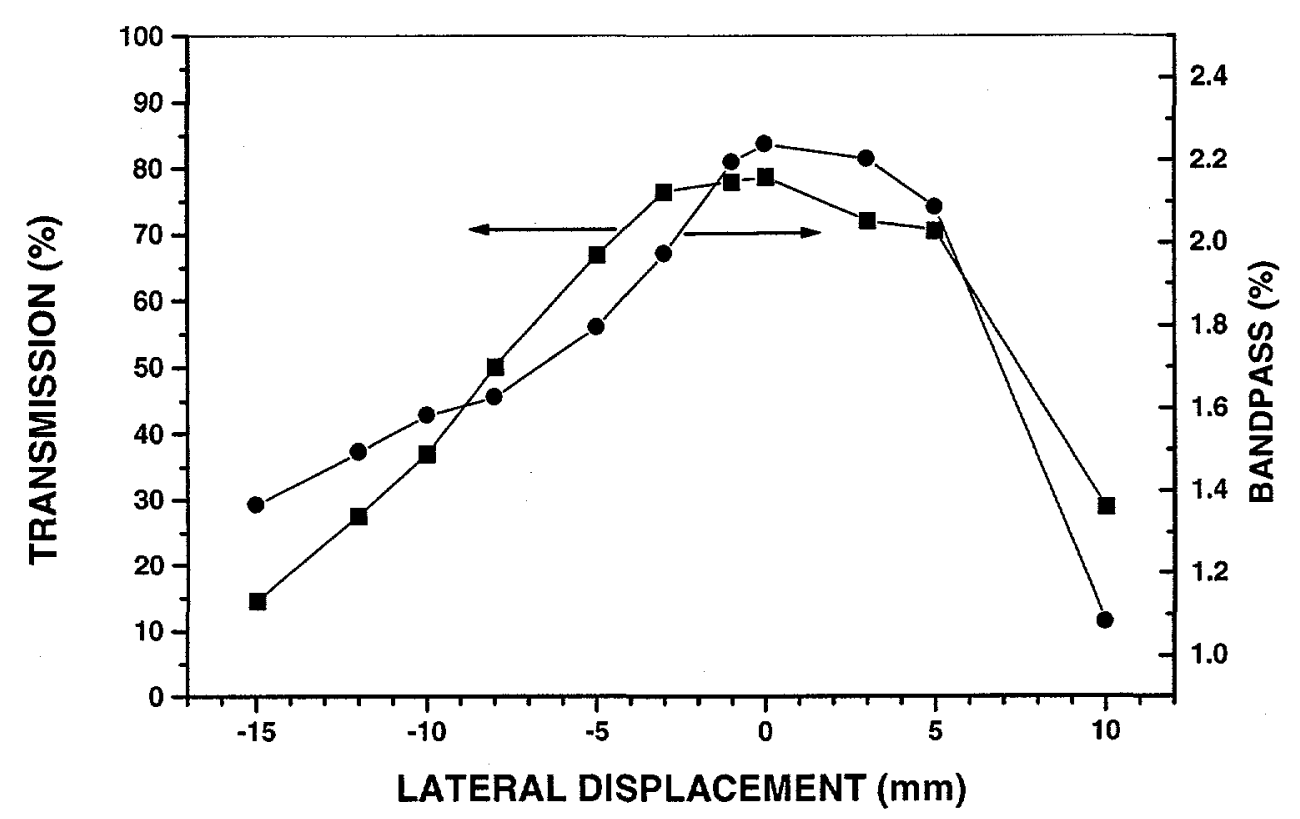

Fig. 6. Transmission (squares) and bandpass (circles) of the double - multilayer monochromator. 


\section{ACKNOWLEDGMENTS}

We acknowledge the assistance of D. Novikov at HASYLAB beamline D4. We also acknowledge D. Windt for the use of his IMD multilayer simulation code. This work was supported in part by the U.S.

Department of Energy, Basic Energy Sciences, Office of Energy Research, under contract No. W-31-109Eng-38, and by DANSYNC.

\section{REFERENCES}

[1] J. Als-Nielsen, Synchrotron Radiation News, Vol.12, p.5 (1999).

${ }^{[2]}$ C. Liu, J. Erdmann, A. Macrander, "The APS Coating Facilities", SRI-CAT Newsletter, Vol.3, pp.2-4, April 1997, http://www.aps.anl.gov/sricat/news.html.

${ }^{[3]}$ D. L. Windt, Computers in Physics, Vol. 12, p. 360 (1998). 